\title{
Unravelling the Functions of Regulatory T Cells during Infection
}

\author{
Tania Rahman ${ }^{1,2 *}$, Md Ferdous Seraj ${ }^{3}$, Annelise Casellato ${ }^{4}$ \\ ${ }^{1}$ Department of Biochemistry and Molecular Biology, Bio21 Molecular Science and Biotechnology Institute, University of \\ Melbourne, Melbourne, Australia \\ ${ }^{2}$ Department of Microbiology and Immunology, University of Melbourne at the Peter Doherty Institute for Infection and \\ Immunity, Melbourne, Australia \\ ${ }^{3}$ School of Civil, Environmental and Chemical Engineering, RMIT University, Melbourne, Australia \\ ${ }^{4}$ Departamento de Química Inorganica, Instituto de Química, Universidade Federal do Rio de Janeiro, Rio de Janeiro, Brazil \\ Email: *tania.rahman@du.ac.bd
}

How to cite this paper: Rahman, T., Seraj, M.F. and Casellato, A. (2018) Unravelling the Functions of Regulatory T Cells during Infection. Open Journal of Medical Microbiology, 8, 118-131.

https://doi.org/10.4236/ojmm.2018.84011

Received: October 22, 2018

Accepted: November 27, 2018

Published: December 11, 2018

Copyright () 2018 by authors and Scientific Research Publishing Inc. This work is licensed under the Creative Commons Attribution International License (CC BY 4.0).

http://creativecommons.org/licenses/by/4.0/

\begin{abstract}
Accumulating evidences have suggested that Treg have an active role in the regulation of immunity to infection. Treg suppress not only autoimmune responses but also other immune responses for instance, during acute infections, against commensal microbes in inflammatory diseases or during chronic illness. Treg have been shown to limit exacerbated inflammation to avoid collateral tissue damage. Treg are also suggested to provide early protective responses in some viral infections as the permitting timely entry of effector cells in infected tissue. Furthermore, Treg have been shown to contribute to form memory pool after resolution of infection. In this review, we survey and analysis our current knowledge and relative dynamics of Treg in a wide range of infection settings and elaborate the examples in which these cells are of critical importance in conferring tolerance, suppressing pathogenesis, inducing protection and optimizing immunity to eliminate infection.
\end{abstract}

\section{Keywords}

Treg Suppression, CD4 T-Cell Response, CD8 T-Cell Response, CD25 $5^{+}$Treg, RAG-1-Deficient mice, Foxp $3^{\text {DTR }}$ Mice, DEREG Mice, Colonic Treg

\section{Introduction}

Treg are developmentally and functionally different from conventional $\mathrm{T}$ cells. Treg are initially characterized as expressing a $\mathrm{CD} 4^{+} \mathrm{CD} 25^{\text {high }}$ phenotype [1] [2]. However, as CD25 is expressed on other activated T cells and there are some Treg in the peripheral tissues which do not express CD25 limiting the use of this 
marker for Treg [3] [4] [5] [6]. To date, the most specific marker identified for the classification of Treg is expression of the transcription factor recognized as forkhead box P3 (Foxp3) [7], which has been exhibited to be expressed specifically in $\mathrm{CD}^{+} \mathrm{T}$ cells. In mice, neither activated $\mathrm{CD} 4^{+} \mathrm{T}$ cells nor differentiated Th1/Th2 cells express Foxp3 [8] [9]. Treg constitute 5\% to $10 \%$ of CD4 ${ }^{+} \mathrm{T}$ cells. In the steady state, they are generated in the thymus and can be induced from naïve $\mathrm{CD} 4^{+} \mathrm{T}$ cells in the periphery. Preliminary studies with Treg were based on their role in dominant tolerance and development of autoimmune disease. However, a handful of studies indicate that Treg play roles in the development of allergic diseases (reviewed in [10]), in the suppression of anti-tumour immunity [11], during pathogen infection (reviewed in [12]) and in controlling responses to commensal microbes in inflammatory diseases [13]. Treg are well known for their immunosuppressive role of varying immune cells including non-Treg $\mathrm{CD}^{+} \mathrm{T}$ cells [14], $\mathrm{CD} 8^{+} \mathrm{T}$ cells [15], dendritic cells (DC) [16], B cells [17], Th17 cells [18], natural killer (NK) cells [19], macrophages [20] and mast cells [21] which are activated in response to pathogen.

\section{Infection}

A substantial body of evidence has demonstrated an increased recruitment of Treg following infection and accumulation at the sites of infection. For example, Treg have been found to expand in viral infections i.e., hepatitis C [22], friend retrovirus [23], Herpes Simplex Virus-1 [24], Lymphocytic Choriomeningitis Virus [25], in protozoal infections i.e., Plasmodium falciparum [26], Leishmania infantum [27], in fungal infection i.e. Paracoccidioides brasiliensis [28] and bacterial infection i.e., Mycobacterium tuberculosis [29] [30], Helicobacter pylori [31]. In this work, we have investigated the role that Treg have in order to identify various protective and pathological responses during different infection models. We have demonstrated that Treg do indeed play crucial roles in different infection settings.

\subsection{Helicobacter pylori}

It has been reported that Treg suppression was associated with the inability of the host to clear Helicobacter pylori infection [32] [33] [34]. In H. pylori infected mice, Treg accumulated at the site of infection early after bacterial ingestion. However, depletion of CD25 $5^{+}$Treg with PC-61 antibody resulted in severe gastritis with a sharp increase in cytokine expression and increased numbers of mucosal $\mathrm{T}$ cells, $\mathrm{B}$ cells, macrophages and increased titres of $H$ pylori-specific IgG1 and IgG2 antibodies [32]. This increased gastric inflammatory response in CD25-depleted mice was associated with reduced bacterial loads signifying that during $H$. pylori infection, Treg down-modulated gastric immunopathology but at the cost of bacterial eradication. Similar to Rad et al., Lundgren et al. demonstrated that the inability of the host to clear the H. pylori infection was a consequence of pathogen-specific regulatory $\mathrm{T}$ cells that actively suppress $\mathrm{T}$-cell re- 
sponses [33]. They showed that $H$. pylori-infected individuals have impaired memory CD4 T-cell responses that are linked to the presence of $H$. pylori-specific Treg that actively suppress the responses. On the contrary, Kaparakis and co-workers demonstrated that depletion of $\mathrm{CD} 25^{+}$Treg prior to and during infection did not influence bacterial colonization or severity of gastritis in $H$. pylori infection [35]. Depletion of CD25 $5^{+}$Treg resulted increased Helicobacter-specific antibody levels and an altered isotype distribution.

\subsection{Herpes Simplex Virus}

Treg normalize disease intensity associated with virus induced inflammatory lesions. Suvas and co-workers [24] demonstrated that immunity to Herpes simplex virus (HSV) was dependent upon a protective $\mathrm{CD} 8^{+} \mathrm{T}$ cell response. In this study, PC-61 mediated depletion of Treg generated an amplified $\mathrm{CD}^{+} \mathrm{T}$ cell response resulting an efficient viral clearance [24]. In contrast, Lund et al. [36] reported opposite effect on depletion of Treg. They found an exacerbated viral burden in mucosa and nervous system following depletion of Treg using Foxp $3^{\text {DTR }}$ mice. Also, Treg depletion profoundly reduced effector cell migration and secretion of inflammatory cytokines at the site of infection suggesting a protective role of Treg in herpes virus infection [36].

\subsection{Mycobacterium tuberculosis}

Treg check efficient clearance of bacteria during Mycobacterium tuberculosis. Treg-depleted mice infected with $M$. tuberculosis showed a decreased bacterial burden in the lungs with an elevated pathogen-specific effector $\mathrm{T}$ cells [37]. Co-transfer of Treg with Th into RAG-1-deficient mice resulted in suppression of effector $\mathrm{CD}^{+} \mathrm{T}$ cells responsible for protection against M. tuberculosis [29]. In another study, Shafiani and co-workers [38] demonstrated that a small proportion of M. tuberculosis specific Treg, were exclusively capable of suppressing protective immunity. Treg recognising $M$. tuberculosis delayed the priming of effector $\mathrm{CD}^{+}$and $\mathrm{CD}^{+}{ }^{+} \mathrm{T}$ cells in the lung which prolonged the bacterial proliferation and explained the augmented bacterial load found in these mice [38].

\subsection{Leishmania major}

Treg contribute to pathogen persistence and form a memory pool after resolution of the infection. The latency of Leishmania major in the skin was controlled by the prevalence of Treg [39]. During infection, Treg accumulated in the dermis and suppressed the ability of effector cells to clear parasite from the site of infection. Interestingly, this parasite persistence provided the host long-term protection from re-infection.

\subsection{West Nile Virus}

In West Nile virus infection, Treg maintained a resident memory pool of $\mathrm{T}$ cells [40]. During infection, Treg numbers increased in lymphoid organs and infected 
tissues (CNS) and allowed memory formation through promoting antigen persistence [40]. Using Foxp $3^{\text {DTR }}$ mice, they found that Treg-deficient mice had increased numbers of short-lived $\mathrm{CD}^{+} \mathrm{T}$ cells, but the memory $\mathrm{CD}^{+} \mathrm{T}$ cell response was impaired. This suggests that with prevention of pathogen clearance Treg maintain a pool of pathogen-specific memory cells which prevent subsequent rechallenge.

\subsection{Trichuris muris Infection}

The impact of Treg depletion is time and course of infection dependent. Sawant et al. explored the functional role of Treg following intestinal parasite Trichuris muris infection [41]. Early Treg depletion post-infection led to accelerated worm clearance accompanied with reduced Th1-mediated inflammation. This protective immunity was impaired and worm titre augmented when Treg were depleted following establishment of infection.

\subsection{Salmonella typhimurium}

The role of Treg following Salmonella typhimurium infection was demonstrated in which Treg influenced the course of infection [42]. During S. typhimurium infection, depletion of Treg early after infection when the bacterial burden was gradually increasing, the suppressive potency of Treg was decreased which accelerated bacterial eradication. However, depletion of Treg during later phase of infection, when the bacterial burden was slowly decreasing, there was no significant changes in bacterial clearance [42]. Thus, Treg tune the balance between bacterial multiplication and clearance of pathogen during different phases of infection.

\subsection{Retroviral Infection}

Treg mediated suppression of CD8 T cells is a significant factor in the consistency of retroviral infections. Dietze and co-workers using DEREG mice showed that transient ablation of Treg following a chronic retroviral infection helps CD8 $\mathrm{T}$ cells to recover antiviral potency [43]. Furthermore, transient Treg ablation had a long-lasting effect in diminishing chronic virus titre. During Friend virus, a retrovirus infection, depletion of Treg in DEREG mice resulted in a significant increase of FV-specific CD8 T-cell mediated responses [44] [45]. In addition, it significantly diminished FV loads in lymphatic organs however, no evidence of immunopathology to the host was found following depletion.

\subsection{Hepatitis C Virus}

Treg control the mutual host-pathogen interaction during hepatitis $C$ virus infection. Hepatitis $\mathrm{C}$ virus was capable of inducing Treg to exert their suppressive potency on effector $\mathrm{T}$ cells, and thereby promoted HCV persistence [46]. In support of this hypothesis, several groups found a significantly greater proportion of Treg in chronically infected patients compared with spontaneously re- 
covered or normal controls [47] [48]. And the increase in Foxp3 was absolutely correlated with the extent of inflammation and the expression of apoptotic mediators [48]. Depletion of Treg increased HCV-specific CD4, CD8 cell and IFN $\gamma$ activity [47]. However, despite Treg suppress effective immune response against $\mathrm{HCV}$; they protected infected subjects from elevated tissue pathology as demonstrated by lessened histological inflammatory activity in persistent HCV infection. Thus in cases of chronic infection, generation of Treg appear to be advantageous to both the pathogen and the host by promoting persistence of infection and limiting immune-mediated pathology.

In contrast to chronic infections, where excessive number of Tregs leads to pathogen persistence, Tregs in acute infections might aid in limiting immune mediated pathology without delaying viral clearance. For example, in mouse hepatitis virus induced acute encephalitis, Treg play a critical role as their depletion resulted in lethal infection and increased mortality [49]. Also co-transfer of Tregs into infected mice increased survival from $0 \%$ to $50 \%$.

\subsection{Respiratory Syncytial Virus}

There are other acute infection models where Treg have been exhibited to perform a crucial role in limiting immunopathology. For example, in acute pulmonary virus infection by respiratory syncytial virus (RSV), Treg rapidly accumulated in draining LNs and lungs [50] [51]. Fulton and co-workers [50] demonstrated that in vivo depletion of Treg using anti-CD25 mAb before RSV infection resulted in delayed viral clearance along with an early interval in the enrolment of antigen-specific CD8 T cells. Moreover, Treg depletion led to aggravated disease intensity, including enhanced weight loss, airway restriction and morbidity. Lee et al. [51] also observed an augmented weight loss with delayed recovery following ablation of Treg. However, this was associated with increased levels of CD4 and CD8 T cells producing IFN- $\gamma$ and TNF- $\alpha$ in the lung and the viral load was unchanged subsequent Treg depletion. Also, the inflammatory reactions were diminished when Treg numbers were boosted using IL-2 immune complexes [52]. Thus Treg function a pivotal role in regulating the immune responses to acute infection that is the key cause of disease pathology and in resolving inflammation resulting pathogen clearance.

\subsection{Leishmania panamensis}

There are some evidences of chronic infections in which Treg provide a protective role and help to resolve pathogen clearance. Upon infection with Leishmania panamensis, Treg were presented with a dysregulated phenotype [53]. Depletion of Tregs using DEREG mice resulted in increased parasite load, enlarged lesions, and enhanced production of IL-17 and IFN- $\gamma$. Also, adoptive transfer of Tregs from naive mice halted disease progression, lowered parasite burden, and reduced cytokine production (IL-10, IL-13, IL-17 and IFN- $\gamma$ ). Thus, Treg-targeted immunotherapy can be used as a safe and potent component in therapeutic 
strategies to treat chronic illness.

We summarize below the data from some of the principal infection systems, with additional details listed in Table 1.

\subsection{Commensal Microbes}

There is handful of studies in which Treg cross-react with non-pathogenic commensal microbiota in the small and large intestine. Treg are found to suppress microbe-driven intestinal inflammation and Treg repertoire is influenced by the presence of particular commensals or bacterial compounds. For instance, colonization of germ-free mice with commensal microbe altered Schaedler flora (ASF) species resulting in activation and de novo generation of colonic Treg [54] [55]. In multiple murine studies, Tregs have been shown to be induced by commensal microbes. For instance, butyrate, a by-product from commensal metabolism, potentially induced conversion of $\mathrm{T}$ cells in to Treg in the intestine [13]

Table 1. Treg mediated potential mechanisms in protection and immunopathology to mucosal infections.

\begin{tabular}{|c|c|c|}
\hline Microorganisms & Effect of Treg on immunopathology or pathogen load & Refs \\
\hline \multirow[t]{2}{*}{ Helicobacter pylori } & $\begin{array}{l}\text { Treg expand in mucosa, CD25 depletion reduces bacterial burden but generates pathology and } \\
\text { inflammation. }\end{array}$ & [32] [33] \\
\hline & Treg depletion does not influence bacterial colonization or immunopathology & [35] \\
\hline \multirow{2}{*}{ Herpes simplex virus } & Treg ablation generates CD8 T cell response with an efficient viral clearance. & {$[24]$} \\
\hline & Treg depletion associates with exacerbated viral burden in mucosa and nervous system. & [36] \\
\hline \multirow{3}{*}{ Mycobacterium tuberculosis } & Treg depleted mice show decreased bacterial burden in the lungs with pathogen specific effector $\mathrm{T}$ cells. & [37] \\
\hline & $\begin{array}{l}\text { Co-transfer of Treg with Th into RAG-1-deficient mice results in suppression of effector CD } 4 \mathrm{~T} \text { cells, } \\
\text { responsible for protection }\end{array}$ & [29] \\
\hline & Pathogen-specific Tregs activated & [38] \\
\hline Leishmania major & $\begin{array}{l}\text { Treg accumulate in the dermis, suppress the ability of effector cells to clear parasite and provide } \\
\text { long-term protection from re-infection. }\end{array}$ & [39] \\
\hline West nile virus & $\begin{array}{l}\text { Treg expand in lymphoid organs and allow memory formation through promoting antigen } \\
\text { persistence. Treg-deficient mice have impaired number of memory CD8 T cells }\end{array}$ & {$[40]$} \\
\hline Trichuris muris & $\begin{array}{l}\text { Early Treg depletion accelerates worm clearance with reduced Th1 mediated inflammation. However, } \\
\text { the worm titre is augmented when Treg are depleted following infection. }\end{array}$ & {$[41]$} \\
\hline Salmonella typhimurium & $\begin{array}{l}\text { Depletion of Treg early after infection accelerates bacterial eradication. However, depletion during later } \\
\text { phase is associated with no significant changes in bacterial clearance. }\end{array}$ & {$[42]$} \\
\hline Retroviral infection & $\begin{array}{l}\text { Transient ablation of Treg following a chronic retroviral infection helps CD8 T cells to recover } \\
\text { antiviral potency. }\end{array}$ & {$[43]$} \\
\hline Friend virus & $\begin{array}{l}\text { Depletion of Treg results in a significant increase of FV-specific CD8 T-cell mediated responses which } \\
\text { diminishes FV loads in lymphatic organs }\end{array}$ & [44] [45] \\
\hline Hepatitis $\mathrm{C}$ virus & $\begin{array}{l}\text { Hepatitis } \mathrm{C} \text { virus induces Treg to exert their suppressive potency on effector T cells and promotes HCV } \\
\text { persistence }\end{array}$ & {$[46]$} \\
\hline \multirow{3}{*}{ Respiratory syncytial virus } & Treg rapidly accumulates in draining LNs and lungs & {$[50][51]$} \\
\hline & $\begin{array}{l}\text { Depletion of Treg results delayed viral clearance, aggravated disease intensity, including enhanced weight } \\
\text { loss, airway restriction and morbidity. }\end{array}$ & {$[50]$} \\
\hline & Augmented weight loss with delayed recovery following ablation of Treg. & {$[51]$} \\
\hline Leishmania panamensis & $\begin{array}{l}\text { Depletion of Tregs results increased parasite load, enlarged lesions, and enhanced production of IL-17 } \\
\text { and IFN- } \gamma \text {. Adoptive transfer of Tregs halts disease progression, lowers parasite burden, and reduces } \\
\text { cytokine production. }\end{array}$ & {$[53]$} \\
\hline
\end{tabular}


[56], through butyrate-mediated histone $\mathrm{H} 3$ acetylation in the Foxp3 promoter [56]. Polysaccharide A (PSA) from B. fragilis potentially induced Treg and resolved experimental colitis [57]. The CNRZ327-component from Lactobacillus delbrueckii induced Treg in colonic tissue [58].

During early life, administration of Clostridium species, a gram positive bacteria,in conventional mice provided resistance to colitis and systemic antibody responses signifying a novel therapeutic approach to autoimmunity. Colonization of mice with Clostridium species from clusters IV, XIVa, and XVIII isolated from human faeces stimulated Treg generation and also increased the production of anti-inflammatory cytokine IL-10 [59] [60]. This Treg induction was mediated through TGF $\beta$ and it protected mice from DSS induced colitis in colon and retained intestinal homeostasis. Also the caecal extracts had high concentrations of short chain fatty acid (SCFA) suggesting that production of SCFA by Clostridia is a contributing factor for the increase in the Treg numbers. Expression of GPR43, a SCFA receptor on colonic Treg has been suggested to promote Treg induction in response to orally administered SCFA [61]. GPR43 signaling has been demonstrated to confer protection in an experimental model of colitis induced on adoptive T-cell transfer into lymphopenic recipients [55].

Tissue inflammation and autoimmune proliferative response following depletion of Treg were analogous in germ free and conventional mice [62]. However, in GF mice lacking in Treg, the inflammation was more intense and pancreatitis was strikingly elevated compared with Treg depleted conventional mice. This suggests the critical role of Treg in subduing reactivity to gut flora. Hence, microbiota colonization driven Treg response is a central process to induce and sustain host-intestinal and microbial mutualistic interaction and existence.

\subsection{Treg in Cancer}

Treg alter antigen-specific immunity and are believed to be responsible for diminished anticancer immune response. Morse and co-workers [63] investigated the immune responses in individuals with advanced cancer following ablation of Treg with CD25 ${ }^{\text {high }}$ targeting immunotoxin (denileukin diftitox). They found an elevated antigen specific $\mathrm{T}$ cell response of cancer vaccines after Treg depletion. However, from experiments with Feline immunodeficiency virus (FIV), it was difficult to predict whether Treg cells play a beneficial or a detrimental role during FIV infection [64] [65]. Treg depletion following anti-feline CD25 $\mathrm{mAb}$ in FIV infected cats for 4 weeks did not exacerbate viral replication or FIV-specific immune responses or proinflammatory cytokine production. However, cats receiving CD25 were able to produce a robust humoral response to new mouse monoclonal antibody [64] [65]. Thus transient Treg depletion following chronic HIV-1 infection could offer an insight for therapeutic vaccination.

\section{Concluding Remarks}

Several studies of infection have indicated that, though the presence of Treg does 
not participate in disease progression, depletion of Treg results in increased effector responses, supporting pathogen clearance and thus acting as suppressive cell. For example, in $H$. pylori infection, Treg ablation led to decreased bacterial burden, yet increased gastric inflammation [32]. In M. tuberculosis, Treg ablation resulted decreased bacterial load in lung and elevated effector T cells [37]. In Salmonella enterica infection, Treg depletion boosted clearance and produced memory T cells [42]. In Strongyloides ratti infection, Treg depletion reduced worm burden [66] and in cerebral malaria, Treg depletion alleviated disease pathology [67].

However, not all studies have revealed that Treg function to control effector activation. Paradoxically, it has been shown that Treg provide protective responses in some pathogen infections permitting timely entry of effector cells in infected tissue. Although not much appreciated, some of the protective functions of Treg cells are characterized as their depletion resulted in more severe infection. For example, in Mouse Hepatitis Virus induced acute encephalitis, Treg depletion led to lethal infection and resulted increased mortality [49]. In Herpes Simplex Virus infection, Treg ablation resulted in loss of immunity through reduced effectors at site of infection [36]. In Respiratory Syncytial Virus infection, Treg ablation resulted augmented weight loss, delayed viral clearance, delayed recovery in the lung and delayed recruitment of CD8 cells [50] [51]. Augmented tissue damage in RSV infection was also demonstrated by another group [68] in which inflammatory reactions were diminished while numbers of Treg were enhanced with IL-2 immune complexes [52]. Treg-deficient mice developed lethal West Nile fever at a higher rate than controls [69]. In Theiler's virus infection, depletion of Treg in resistant mouse strains made them more susceptible to CNS lesions [70]. Clostridium species, a gram + bacteria, mediates Treg induction through TGF $\beta$ and protects against DSS induced colitis [59].

Depletion or reduction of Treg thus augments effective immune responses against pathogenic microbes in most cases while their diminution sometimes reduces effector cell trafficking to the site of infection and might hamper the development of robust secondary immune response following subsequent rechallenge. Also, depletion of Treg in some acute infection models exacerbates disease pathology along with lack of trafficking of effector cells. Hence, Treg providing either suppressive or protective potency over the effector cells either controls or augments the extent of physiological immune response against pathogens and associated immunopathology.

\section{Conflicts of Interest}

The authors declare no conflict of interest that could be perceived to bias the work.

\section{References}

[1] Baecher-Allan, C., et al. (2003) $\mathrm{CD}^{+} \mathrm{CD} 25^{+}$Regulatory Cells from Human Periph- 
eral Blood Express Very High Levels of CD25 ex vivo. Novartis Foundation Symposia, 252, 67-88, 88-91, 106-114.

[2] Baecher-Allan, C., et al. (2001) $\mathrm{CD}^{+} \mathrm{CD} 25^{+}$High Regulatory Cells in Human Peripheral Blood. The Journal of Immunology, 167, 1245-1253.

https://doi.org/10.4049/jimmunol.167.3.1245

[3] Leithauser, F., et al. (2006) Foxp3-Expressing CD103 ${ }^{+}$Regulatory T Cells Accumulate in Dendritic Cell Aggregates of the Colonic Mucosa in Murine Transfer Colitis. The American Journal of Pathology, 168, 1898-1909.

https://doi.org/10.2353/ajpath.2006.050228

[4] Needham, D.J., Lee, J.X. and Beilharz, M.W. (2006) Intra-Tumoural Regulatory T Cells: A Potential New Target in Cancer Immunotherapy. Biochemical and Biophysical Research Communications, 343, 684-691.

https://doi.org/10.1016/j.bbrc.2006.03.018

[5] Sakaguchi, S. (2005) Naturally Arising Foxp3-Expressing CD $25^{+} \mathrm{CD} 4^{+}$Regulatory T Cells in Immunological Tolerance to Self and Non-Self. Nature Immunology, 6, 345-352. https://doi.org/10.1038/ni1178

[6] Buckner, J.H. (2010) Mechanisms of Impaired Regulation by CD4(+)CD25(+)FOXP3(+) Regulatory T Cells in Human Autoimmune Diseases. Nature Reviews Immunology, 10, 849-859. https://doi.org/10.1038/nri2889

[7] Fontenot, J.D. and Rudensky, A.Y. (2005) A Well Adapted Regulatory Contrivance: Regulatory T Cell Development and the Forkhead Family Transcription Factor Foxp3. Nature Immunology, 6, 331-337. https://doi.org/10.1038/ni1179

[8] Fontenot, J.D., Gavin, M.A. and Rudensky, A.Y. (2003) Foxp3 Programs the Development and Function of $\mathrm{CD} 4{ }^{+} \mathrm{CD} 25^{+}$Regulatory T Cells. Nature Immunology, 4 , 330-336. https://doi.org/10.1038/ni904

[9] Hori, S., Nomura, T. and Sakaguchi, S. (2003) Control of Regulatory T Cell Development by the Transcription Factor Foxp3. Science, 299, 1057-1061.

https://doi.org/10.1126/science.1079490

[10] Seroogy, C.M. and Gern, J.E. (2005) The Role of T Regulatory Cells in Asthma. Journal of Allergy and Clinical Immunology, 116, 996-999. https://doi.org/10.1016/j.jaci.2005.07.015

[11] Nishikawa, H. and Sakaguchi, S. (2010) Regulatory T Cells in Tumor Immunity. International Journal of Cancer, 127, 759-767. https://doi.org/10.1002/ijc.25429

[12] Maizels, R.M. and Smith, K.A. (2011) Regulatory T Cells in Infection. Advances in Immunology, 112, 73-136. https://doi.org/10.1016/B978-0-12-387827-4.00003-6

[13] Arpaia, N., et al. (2013) Metabolites Produced by Commensal Bacteria Promote Peripheral Regulatory T-Cell Generation. Nature, 504, 451-455.

https://doi.org/10.1038/nature12726

[14] Aandahl, E.M., et al. (2004) Human CD4 ${ }^{+} \mathrm{CD} 25^{+}$Regulatory T Cells Control T-Cell Responses to Human Immunodeficiency Virus and Cytomegalovirus Antigens. Journal of Virology, 78, 2454-2459. https://doi.org/10.1128/JVI.78.5.2454-2459.2004

[15] McNally, A., et al. (2011) CD4 ${ }^{+} \mathrm{CD} 25^{+}$Regulatory T Cells Control CD8+ T-Cell Effector Differentiation by Modulating IL-2 Homeostasis. Proceedings of the National Academy of Sciences of the United States of America, 108, 7529-7534. https://doi.org/10.1073/pnas.1103782108

[16] Terme, M., et al. (2008) Regulatory T Cells Control Dendritic Cell/NK Cell Cross-Talk in Lymph Nodes at the Steady State by Inhibiting $\mathrm{CD} 4^{+}$Self-Reactive T 
Cells. The Journal of Immunology, 180, 4679-4686.

https://doi.org/10.4049/jimmunol.180.7.4679

[17] Iikuni, N., Lourenço, E.V., Hahn, B.H. and La Cava, A. (2009) Cutting Edge: Regulatory T Cells Directly Suppress B Cells in Systemic Lupus Erythematosus. The Journal of Immunology, 183, 1518-1522. https://doi.org/10.4049/jimmunol.0901163

[18] Chaudhry, A., et al. (2009) $\mathrm{CD}^{+}$Regulatory T Cells Control $\mathrm{T}_{\mathrm{H}} 17$ Responses in a Stat3-Dependent Manner. Science, 326, 986-991. https://doi.org/10.1126/science.1172702

[19] Ghiringhelli, F., Ménard, C., Martin, F. and Zitvogel, L. (2006) The Role of Regulatory T Cells in the Control of Natural Killer Cells: Relevance during Tumor Progression. Immunological Reviews, 214, 229-238. https://doi.org/10.1111/j.1600-065X.2006.00445.x

[20] Taams, L.S., et al. (2005) Modulation of Monocyte/Macrophage Function by Human $\mathrm{CD} 4^{+} \mathrm{CD} 25^{+}$Regulatory T Cells. Human Immunology, 66, 222-230. https://doi.org/10.1016/j.humimm.2004.12.006

[21] Gri, G., et al. (2008) CD $4^{+} \mathrm{CD} 25^{+}$Regulatory T Cells Suppress Mast Cell Degranulation and Allergic Responses through OX40-OX40L Interaction. Immunity, 29, 771-781. https://doi.org/10.1016/j.immuni.2008.08.018

[22] Ebinuma, H., et al. (2008) Identification and in Vitro Expansion of Functional Antigen-Specific CD25 $5^{+}$FoxP $^{+}$Regulatory T Cells in Hepatitis C Virus Infection. Journal of Virology, 82, 5043-5053. https://doi.org/10.1128/JVI.01548-07

[23] Iwashiro, M., et al. (2001) Immunosuppression by CD4 ${ }^{+}$Regulatory T Cells Induced by Chronic Retroviral Infection. Proceedings of the National Academy of Sciences of the United States of America, 98, 9226-9230. https://doi.org/10.1073/pnas.151174198

[24] Suvas, S., Kumaraguru, U., Pack, C.D., Lee, S. and Rouse, B.T. (2003) CD4 ${ }^{+}$CD $25^{+}$T Cells Regulate Virus-Specific Primary and Memory $\mathrm{CD}^{+} \mathrm{T}$ Cell Responses. The Journal of Experimental Medicine, 198, 889-901. https://doi.org/10.1084/jem.20030171

[25] Filippi, C.M., Estes, E.A., Oldham, J.E. and von Herrath, M.G. (2009) Immunoregulatory Mechanisms Triggered by Viral Infections Protect from Type 1 Diabetes in Mice. Journal of Clinical Investigation, 119, 1515-1523. https://doi.org/10.1172/JCI38503

[26] Brustoski, K., et al. (2006) Reduced Cord Blood Immune Effector-Cell Responsiveness Mediated by $\mathrm{CD}^{+}$Cells Induced in Utero as a Consequence of Placental Plasmodium falciparum Infection. The Journal of Infectious Diseases, 193, 146-154. https://doi.org/10.1086/498578

[27] Rodrigues, O.R., Marques, C., Soares-Clemente, M., Ferronha, M.H. and Santos-Gomes, G.M. (2009) Identification of Regulatory T Cells during Experimental Leishmania infantum Infection. Immunobiology, 214, 101-111. https://doi.org/10.1016/j.imbio.2008.07.001

[28] Cavassani, K.A., et al. (2006) Systemic and Local Characterization of Regulatory T Cells in a Chronic Fungal Infection in Humans. The Journal of Immunology, 177, 5811-5818. https://doi.org/10.4049/jimmunol.177.9.5811

[29] Kursar, M., et al. (2007) Cutting Edge: Regulatory T Cells Prevent Efficient Clearance of Mycobacterium tuberculosis. The Journal of Immunology, 178, 2661-2665. https://doi.org/10.4049/jimmunol.178.5.2661

[30] Ordway, D.J., et al. (2011) Mycobacterium bovis BCG-Mediated Protection against 
W-Beijing Strains of Mycobacterium tuberculosis Is Diminished Concomitant with the Emergence of Regulatory T Cells. Clinical and Vaccine Immunology, 18, 1527-1535. https://doi.org/10.1128/CVI.05127-11

[31] Kandulski, A., et al. (2008) Naturally Occurring Regulatory T Cells (CD4 ${ }^{+}$, CD25 $5^{\text {high }}$, $\mathrm{FOXP}^{+}$) in the Antrum and Cardia Are Associated with Higher H. pylori Colonization and Increased Gene Expression of TGF-Beta1. Helicobacter, 13, 295-303. https://doi.org/10.1111/j.1523-5378.2008.00612.x

[32] Rad, R., et al. (2006) CD $25^{+} / \mathrm{Foxp}^{+} \mathrm{T}$ Cells Regulate Gastric Inflammation and Helicobacter pylori Colonization in Vivo. Gastroenterology, 131, 525-537. https://doi.org/10.1053/j.gastro.2006.05.001

[33] Lundgren, A., Suri-Payer, E., Enarsson, K., Svennerholm, A.-M. and Lundin, B.S. (2003) Helicobacter pylori-Specific $\mathrm{CD}^{+} \mathrm{CD} 25^{\text {high }}$ Regulatory T Cells Suppress Memory T-Cell Responses to $H$. pylori in Infected Individuals. Infection and Immunity, 71, 1755-1762. https://doi.org/10.1128/IAI.71.4.1755-1762.2003

[34] Raghavan, S., Suri-Payer, E. and Holmgren, J. (2004) Antigen-Specific in Vitro Suppression of Murine Helicobacter pylori-Reactive Immunopathological T Cells by $\mathrm{CD} 4{ }^{+} \mathrm{CD} 25^{+}$Regulatory T Cells. Scandinavian Journal of Immunology, 60, 82-88. https://doi.org/10.1111/j.0300-9475.2004.01447.x

[35] Kaparakis, M., et al. (2008) Macrophages Are Mediators of Gastritis in Acute Helicobacter pylori Infection in C57BL/6 Mice. Infection and Immunity, 76, 2235-2239. https://doi.org/10.1128/IAI.01481-07

[36] Lund, J.M., Hsing, L., Pham, T.T. and Rudensky, A.Y. (2008) Coordination of Early Protective Immunity to Viral Infection by Regulatory T Cells. Science, 320, 1220-1224. https://doi.org/10.1126/science.1155209

[37] Scott-Browne, J.P., et al. (2007) Expansion and Function of Foxp3-Expressing T Regulatory Cells during Tuberculosis. The Journal of Experimental Medicine, 204, 2159-2169. https://doi.org/10.1084/jem.20062105

[38] Shafiani, S., Tucker-Heard, G., Kariyone, A., Takatsu, K. and Urdahl, K.B. (2010) Pathogen-Specific Regulatory T Cells Delay the Arrival of Effector T Cells in the Lung During Early Tuberculosis. The Journal of Experimental Medicine, 207, 1409-1420. https://doi.org/10.1084/jem.20091885

[39] Belkaid, Y., Piccirillo, C.A., Mendez, S., Shevach, E.M. and Sacks, D.L. (2002) $\mathrm{CD} 4{ }^{+} \mathrm{CD} 25^{+}$Regulatory T Cells Control Leishmania Major Persistence and Immunity. Nature, 420, 502-507. https://doi.org/10.1038/nature01152

[40] Graham, J.B., Da Costa, A. and Lund, J.M. (2014) Regulatory T Cells Shape the Resident Memory T Cell Response to Virus Infection in the Tissues. The Journal of Immunology, 192, 683-690. https://doi.org/10.4049/jimmunol.1202153

[41] Sawant, D.V., et al. (2014) Regulatory T Cells Limit Induction of Protective Immunity and Promote Immune Pathology Following Intestinal Helminth Infection. The Journal of Immunology, 192, 2904-2912. https://doi.org/10.4049/jimmunol.1202502

[42] Johanns, T.M., Ertelt, J.M., Rowe, J.H. and Way, S.S. (2010) Regulatory T Cell Suppressive Potency Dictates the Balance between Bacterial Proliferation and Clearance during Persistent Salmonella Infection. PLoS Pathogens, 6, e1001043.

https://doi.org/10.1371/journal.ppat.1001043

[43] Dietze, K.K., et al. (2011) Transient Depletion of Regulatory T Cells in Transgenic Mice Reactivates Virus-Specific $\mathrm{CD}^{+} \mathrm{T}$ Cells and Reduces Chronic Retroviral Set Points. Proceedings of the National Academy of Sciences of the United States of America, 108, 2420-2425. https://doi.org/10.1073/pnas.1015148108

[44] Zelinskyy, G., Dietze, K., Sparwasser, T. and Dittmer, U. (2009) Regulatory T Cells 
Suppress Antiviral Immune Responses and Increase Viral Loads during Acute Infection with a Lymphotropic Retrovirus. PLoS Pathogens, 5, e1000406. https://doi.org/10.1371/journal.ppat.1000406

[45] Zelinskyy, G., et al. (2009) The Regulatory T-Cell Response during Acute Retroviral Infection Is Locally Defined and Controls the Magnitude and Duration of the Virus-Specific Cytotoxic T-Cell Response. Blood, 114, 3199-3207. https://doi.org/10.1182/blood-2009-03-208736

[46] Sturm, N., et al. (2010) Characterization and Role of Intra-Hepatic Regulatory T Cells in Chronic Hepatitis C Pathogenesis. Journal of Hepatology, 53, 25-35. https://doi.org/10.1016/j.jhep.2010.02.024

[47] Cabrera, R., et al. (2004) An Immunomodulatory Role for CD $4^{+} \mathrm{CD} 25^{+}$Regulatory $\mathrm{T}$ Lymphocytes in Hepatitis C Virus Infection. Hepatology, 40, 1062-1071. https://doi.org/10.1002/hep.20454

[48] Speletas, M., et al. (2011) Foxp3 Expression in Liver Correlates with the Degree but Not the Cause of Inflammation. Mediators of Inflammation, 2011, Article ID: 827565.

[49] Anghelina, D., Zhao, J.X., Trandem, K. and Perlman, S. (2009) Role of Regulatory T Cells in Coronavirus-Induced Acute Encephalitis. Virology, 385, 358-367. https://doi.org/10.1016/j.virol.2008.12.014

[50] Fulton, R.B., Meyerholz, D.K. and Varga, S.M. (2010) Foxp3 ${ }^{+}$CD4 Regulatory T Cells Limit Pulmonary Immunopathology by Modulating the CD8 T Cell Response during Respiratory Syncytial Virus Infection. The Journal of Immunology, 185, 2382-2392. https://doi.org/10.4049/jimmunol.1000423

[51] Lee, D.C., et al. (2010) CD25+ Natural Regulatory T Cells Are Critical in Limiting Innate and Adaptive Immunity and Resolving Disease Following Respiratory Syncytial Virus Infection. Journal of Virology, 84, 8790-8798. https://doi.org/10.1128/JVI.00796-10

[52] Loebbermann, J., Durant, L., Thornton, H., Johansson, C. and Openshaw, P.J. (2013) Defective Immunoregulation in RSV Vaccine-Augmented Viral Lung Disease Restored by Selective Chemoattraction of Regulatory T Cells. Proceedings of the National Academy of Sciences of the United States of America, 110, 2987-2992. https://doi.org/10.1073/pnas.1217580110

[53] Ehrlich, A., et al. (2014) The Immunotherapeutic Role of Regulatory T Cells in Leishmania (Viannia) panamensis Infection. The Journal of Immunology, 193, 2961-2970. https://doi.org/10.4049/jimmunol.1400728

[54] Geuking, M.B., et al. (2011) Intestinal Bacterial Colonization Induces Mutualistic Regulatory T Cell Responses. Immunity, 34, 794-806. https://doi.org/10.1016/j.immuni.2011.03.021

[55] Smith, P.M., et al. (2013) The Microbial Metabolites, Short-Chain Fatty Acids, Regulate Colonic Treg Cell Homeostasis. Science, 341, 569-573. https://doi.org/10.1126/science.1241165

[56] Furusawa, Y., et al. (2013) Commensal Microbe-Derived Butyrate Induces the Differentiation of Colonic Regulatory T Cells. Nature, 504, 446-450. https://doi.org/10.1038/nature12721

[57] Round, J.L. and Mazmanian, S.K. (2010) Inducible Foxp ${ }^{+}$Regulatory T-Cell Development by a Commensal Bacterium of the Intestinal Microbiota. Proceedings of the National Academy of Sciences of the United States of America, 107, 12204-12209. https://doi.org/10.1073/pnas.0909122107

[58] Santos Rocha, C., et al. (2014) Local and Systemic Immune Mechanisms Underlying 
the Anti-Colitis Effects of the Dairy Bacterium Lactobacillus delbrueckii. PLoS ONE, 9, e85923. https://doi.org/10.1371/journal.pone.0085923

[59] Atarashi, K., et al. (2011) Induction of Colonic Regulatory T Cells by Indigenous Clostridium Species. Science, 331, 337-341. https://doi.org/10.1126/science.1198469

[60] Atarashi, K., Umesaki, Y. and Honda, K. (2011) Microbiotal Influence on T Cell Subset Development. Seminars in Immunology, 23, 146-153. https://doi.org/10.1016/j.smim.2011.01.010

[61] Maslowski, K.M., et al. (2009) Regulation of Inflammatory Responses by Gut Microbiota and Chemoattractant Receptor GPR43. Nature, 461, 1282-1286. https://doi.org/10.1038/nature08530

[62] Chinen, T., Volchkov, P.Y., Chervonsky, A.V. and Rudensky, A.Y. (2010) A Critical Role for Regulatory T Cell-Mediated Control of Inflammation in the Absence of Commensal Microbiota. The Journal of Experimental Medicine, 207, 2323-2330. https://doi.org/10.1084/jem.20101235

[63] Morse, M.A., et al. (2008) Depletion of Human Regulatory T Cells Specifically Enhances Antigen-Specific Immune Responses to Cancer Vaccines. Blood, 112, 610-618. https://doi.org/10.1182/blood-2008-01-135319

[64] Mikkelsen, S.R., Reckling, S.K., Egan, E.A. and Dean, G.A. (2010) In Vivo Depletion of $\mathrm{CD} 4{ }^{+} \mathrm{CD} 25^{\text {hi }}$ Regulatory T Cells Is Associated with Improved Antiviral Responses in Cats Chronically Infected with Feline Immunodeficiency Virus. Virology, 403, 163-172. https://doi.org/10.1016/j.virol.2010.04.016

[65] Mikkelsen, S.R., et al. (2011) Partial Regulatory T Cell Depletion Prior to Acute Feline Immunodeficiency Virus Infection Does Not Alter Disease Pathogenesis. PLoS ONE, 6, e17183. https://doi.org/10.1371/journal.pone.0017183

[66] Blankenhaus, B., et al. (2011) Strongyloides ratti Infection Induces Expansion of Foxp3+ Regulatory $\mathrm{T}$ Cells That Interfere with Immune Response and Parasite Clearance in BALB/c Mice. The Journal of Immunology, 186, 4295-4305. https://doi.org/10.4049/jimmunol.1001920

[67] Wu, J.J., Chen, G., Liu, J., Wang, T., Zheng, W. and Cao, Y.-M. (2010) Natural Regulatory T Cells Mediate the Development of Cerebral Malaria by Modifying the Pro-Inflammatory Response. Parasitology International, 59, 232-241. https://doi.org/10.1016/j.parint.2010.02.007

[68] Loebbermann, J., et al. (2012) Regulatory T Cells Expressing Granzyme B Play a Critical Role in Controlling Lung Inflammation during Acute Viral Infection. $\mathrm{Mu}$ cosal Immunology, 5, 161-172. https://doi.org/10.1038/mi.2011.62

[69] Lanteri, M.C., et al. (2009) Tregs Control the Development of Symptomatic West Nile Virus Infection in Humans and Mice. Journal of Clinical Investigation, 119, 3266-3277. https://doi.org/10.1172/JCI39387

[70] Richards, M.H., et al. (2011) Virus Expanded Regulatory T Cells Control Disease Severity in the Theiler's Virus Mouse Model of MS. Journal of Autoimmunity, 36, 142-154. https://doi.org/10.1016/j.jaut.2010.12.005 


\section{Abbreviations}

ASF altered Schaedler flora; $\boldsymbol{B}$. fragilis Bacteroides fragilis, CD Cluster of differentiation; CNS Central Nervous system; DC Dendritic cells; DEREG Depletion of Regulatory T cells; DSS Dextran sulfate sodium; FIV Feline immunodeficiency virus; Foxp3 Forkhead box P3 protein; Foxp $3^{\text {DTR }}$ Forkhead box P3 protein-Diphtheria toxin receptor; FV Friend virus; GF mice Germ-free mice; GPR43 G-Protein Coupled Receptor 43; HCV Hepatitis C virus; H. pylori Helicobacter pylori; HSV Herpes Simplex virus; IFN Interferons; IL interleukins; LCMV Lymphocytic Choriomeningitis Virus; LN Lymph nodes; mAb monoclonal antibodies; Mt Mycobacterium tuberculosis; NK Natural killer cells; PSA Polysaccharide A; RAG-1 Recombination activating gene-1; RSV Respiratory Syncytial Virus; SCFA short chain fatty acid; TGF $\beta$ Transforming Growth Factor beta; Th T helper cells; TNF Tumour Necrosis factor; Treg CD4+Foxp3+ Regulatory T cell; HIV-1 The human immunodeficiency virus-1. 